\title{
The Long Arm of the Digital Tether: Communication with Home during Study Abroad
}

\section{Barbara K. Hofer, Stacey Woody Thebodo, Kristen Meredith, Zoe Kaslow, Alexandra Saunders \\ Middlebury College}

Until fairly recently, when U.S. students left home for college, their contact with family decreased abruptly. They typically learned to make an increasing number of important decisions without parental consultation, and developed in predictable ways toward becoming autonomous, self-regulating adults. Moreover, if they chose to study abroad during college, the distance from home and costs of communication generally meant that they were in even less contact with friends and family, and were expected to benefit from both the cultural immersion and the growing independence such experiences offered. The proliferation of affordable and accessible modes of communication, however - email, smart phones, texting, Skype, Facetime, Facebook, Viber, WhatsApp, for example - has made it possible for college students to connect with those at home with a frequency that would have been unimaginable only a decade ago.

In spite of a growing sense of concern about how such dramatically increased potential for communication might influence the study abroad experience (Huesca, 2013), only limited research on the subject has been conducted (e.g., Mikal \& Grace, 2012). This study expands our prior research on student-parent communication during the college years to students studying abroad by exploring their connections with friends and family at home and how this technological connectedness may be related to the study abroad experience.

\section{The Changing Communication Landscape}

The potential to digitally connect with others has grown in recent years at an unprecedented rate. In 2015, two thirds of Americans owned a smartphone (Smith, 2015), a number that continues to grow. This access makes it possible to connect with anyone at any time, whether through calls or texting or various message systems, as well as utilizing a vast array of social media. The modes of connection continue to proliferate, and adolescents and college students continue to migrate to new platforms; while Facebook, started in 2004, is still widely in use, apps such as Instragram and Snapchat have become ever more popular among young people. The growing frequency of use has raised concerns among parents, educators, and researchers, and recent research suggests there are neurological rewards for the social endorsement provided by "likes", for example (Sherman, Payton, Hernández, Greenfield, \& Dapretto, 2016).

Although the communication landscape is ever changing, it seems unlikely that the clock can be turned back to a time when individuals ventured off into the world with few connections to family 
and friends. It is important, however, to understand the implications of current communication patterns and their influence on human development (e.g., Turkle, 2011), as well as how individuals can become mindful of the implications and learn what might be under their own control. Education abroad administrators and parents can also benefit from understanding the developmental implications of the choices made about communication.

\section{Autonomy, Self-regulation, and Student-Parent Communication}

Autonomy is viewed by psychologists as a key psychosocial task that is particularly salient during adolescence and continues to develop in the period of emerging adulthood, roughly ages 1825 (Arnett, 2000, 2015). As they become more autonomous, individuals are expected to become more capable of governing and regulating their own behavior and taking responsibility for their actions, with less involvement from parents (Steinberg, 2001). Autonomy has been linked to both educational and occupational success, in college and beyond (Bell, Allen, Hauser, \& O'Connor, 1996). In the transition from high school to college, students have typically been expected to take increasing initiative in managing their time, organizing their work, and pursuing their goals. Such self-regulated learning, involving the regulation of goals, motivation and behavior (Hofer, Yu \& Pintrich, 1998), also has numerous benefits for college success (Ross et al., 2003). College is a particularly important time for "learning to learn" (Hofer \& Yu, 2003) and for development of these self-regulatory skills.

In the past, many of these changes during the college years have taken place as students and parents moved from the familiarity of daily contact to far less frequent connection, perhaps a weekly phone call and occasional letters. The rise in a wide array of forms of communication and the decline in costs, especially with unlimited calling plans and smart phones, has allowed for parental contact to become more frequent and immediate, potentially influencing students' developmental processes. From a series of studies by the first author, we found that college students who are in the most frequent contact with their parents are the least likely to be autonomous (Hofer \& Moore, 2010; Hofer, Souder, Kennedy, Fullman, \& Hurd, 2009). Some parents have utilized new modes of connection to continue regulating from afar, advising and sometimes directing their college-age kids about decisions both small and large. This is potentially problematic: our research shows that parental regulation during college has shown no beneficial correlations, and that student selfregulation, by contrast, is positively correlated with overall satisfaction with college, enthusiasm for learning, positive relationships with both peers and professors, and overall grade point average (Hofer, 2008). Furthermore, we found that parents who were highly regulating of their children in high school were most likely to continue to do so not only in college but also in the early years after college (Hofer \& Moore, 2010), with technology providing the means for continuing patterns of behavior that may be counterproductive.

Our prior research also indicates just how pervasive student-parent contact has become during the college years. In our initial study of first-semester college students at a liberal arts college, launched at a time when cell phones were first becoming commonplace on college campuses, we found that students were communicating with their parents 10.4 times per week, when all forms of communication were combined, with cell phone calls as the most common mode of contact, followed by email (Hofer, Kennedy, \& Hurd, 2006). Extending that study to all four years of college and to students enrolled in a large research university as well as a liberal arts college, we expected to 
see a decline in contact over the four years of college, and possible differences between institutional types. What we found was that students were connecting with parents an average of 13.4 times per week and that these rates did not vary in any of the predicted ways (Hofer \& Moore, 2010), suggesting that this was a ubiquitous phenomenon, which has seemed even more evident in subsequent studies. With the increase in modes of communication, our research in the 2012-13 academic year showed that students were in contact with parents an average of 22.1 times per week, with texting fueling the increase, even as other forms of communication continued at similar rates. In all of these studies, perhaps surprisingly, students appeared to be initiating the contact nearly as much as their parents, and reported they were relatively satisfied with the amount of contact, except for a notable desire to have more communication with fathers.

Against this backdrop of research, and with rising concern being expressed by higher education and study abroad administrators (Engle \& Engle, 2002; Engle \& Engle, 2012; Huesca, 2013; Wooley, 2013), we were interested in exploring patterns of communication with home during study abroad and how this might be related to development and learning during this period, more broadly conceptualized to include developmental goals particular to study abroad. We were interested not only in communication with parents, but also with friends, as well as the use of Facebook as a means of staying connected with home and the lives of friends and family.

\section{Study Abroad and Student Development and Learning}

Education abroad has long been associated with students' cognitive, psychosocial, and interpersonal development (Twombly, Salisbury, Tumanut, \& Klute, 2012). Importantly, one of the Forum on Education Abroad's Standards of Good Practice for education abroad programs is: "The organization's mission, goals, and operations prioritize student learning and development." The Standards define student development as including "independence, self-direction, leadership skills, service orientation, maturity, [and] tolerance for ambiguity" (Forum on Education Abroad, 2015). Overall goals for the education abroad experience often include facilitating students' intellectual, academic, and personal growth and fostering linguistic skills, as well as increasing students' global awareness and cross-cultural understanding and communication (Hoffa \& DePaul, 2010; Ingraham \& Peterson, 2004; Sutton \& Rubin, 2004, Twombly et al., 2012). Recently, the education abroad field has seen a marked emphasis on furthering study abroad students' intercultural competence development as an important goal for education abroad. Defining and measuring intercultural competence has taken on a much greater prominence, including developing and advancing the tools for measuring students' learning and their achievement of the aforementioned goals (Deardorff, 2011; Twombly et al., 2012; Vande Berg, Paige, \& Lou, 2012).

The traditional notion of study abroad emphasizes "cultural immersion" and the concept that exposing students to other cultures, separating them from home and the familiar, facilitates learning and development (Root \& Ngampornchai, 2012; Twombly et al., 2012; Vande Berg et al., 2012;). As such, the traditional education abroad experience is modeled on the theory that face-to-face encounters with individuals from the host culture provide the most learning (Mikal \& Grace, 2012). This "immersion assumption" gave rise to emphasis being placed on program components such as direct enrollment in a host country university, homestays with local families, and providing activities to push students to interact as much as possible with people from the host country. More recently, however, education abroad professionals have sought to examine the immersion assumption 
(Hammer, 2012). As this paradigm is shifting, more research is being conducted on the factors that affect study abroad learning and outcomes, such as program design aspects (e.g., program length, linguistic factors, types of housing, etc.) and interventions (e.g., cultural mentoring, pre-departure and re-entry sessions, courses, and texts) (Cohen, Paige, Shively, Emert, \& Hoff, 2005; Sutton \& Rubin, 2004; Vande Berg, Connor-Linton, \& Paige, 2009; Paige \& Vande Berg, 2012; Vande Berg, Quinn \& Menyhart, 2012, Salisbury, An, \& Pascarella, 2013).

An important factor that has not been extensively studied, however, is the introduction of modern technology to the study abroad experience and how it may influence the attainment of expected goals of the education abroad experience, student learning and intercultural competence development. With readily accessible technology at their fingertips, students abroad are no longer separated completely from friends and family at home, and may be less immersed in the new culture (Engle \& Engle, 2012). Although there have been a few studies examining the role of technology in study abroad, limited research exists on students' technological connectedness with home and the influence on student development and learning. The limited research that has been done has shown both positive and negative impacts of technology on the education abroad experience.

Notably, Engle and Engle (2012) found that student learning outcomes, including both language acquisition and intercultural competence, "suffered dramatically" after providing campus wide access to wifi, after years of intentionally restricting Internet and email access to the computer lab. With other program variables unchanged, when these results were shared with students in subsequent semesters and students were then given the choice of signing up for wifi at the center or not, all of the students opted for going without wifi, and outcomes assessments returned to the higher scores seen before wifi access was granted.

Positive influences of technology abroad relate to the convenience of navigation tools and access students have to information about the host country, easing their transition to the new environment (Wooley, 2013). However, distractions provided by technology can also have a negative influence, when students seem to be more interested in presenting their experience on social media rather than actually being present in the experience itself, thus preventing cultural integration (Wooley, 2013). Internet use also can enhance the education abroad experience through the creation of "virtual environments" with online communities, providing an important source of "perceived available support" (Mikal \& Grace, 2012). This perceived support can potentially lead to decreased stress and increased cultural integration, risk-taking, and goal achievement (Mikal \& Grace, 2012). However, in contrast to perceived available support, students' actual reliance on online support networks, termed "received support," can potentially result in higher stress levels, lower goal achievement, and less immersion in the host culture. Some research suggests that students may be using online social networks to translate to face-to-face interactions with individuals from the host country (Mikal 2011); however, other research has found that students who rely on electronic support networks from home are not connecting online and forming supportive friendships with individuals from their host country (Mikal \& Grace, 2012).

\section{The Current Study}

The goal of this exploratory study was to further the inquiry regarding students' technological connectedness and communication with home during study abroad. We explored the form, 
frequency, and initiation of students' contacts with family and friends, and the connection between contact with home and variables such as autonomy, self-regulation, and cultural and personal learning. We were also interested in student perceptions of the limitations and use of technology while abroad, as well as the use of Facebook and perceptions of its influence. Our primary research questions were as follows:

1. How connected are students with parents while studying abroad and how do they feel about it?

2. How is the frequency of student communication with their parents correlated with psychosocial measures of autonomy and self-regulation?

3. How connected are students with friends while studying abroad, how much do they use Facebook, and how do they feel about it?

4. How satisfied are students with their study abroad experiences and how does their learning abroad relate to communication with family and friends?

5. What advice would participants give to others studying abroad?

\section{Method}

\section{Participants}

Participants in this study were 417 students studying at a Danish study abroad program that enrolled students from 165 institutions. Of these participants, $76 \%$ were female, only slightly higher than within the overall population of the program (71\% female), and $84 \%$ indicated that they were White/Caucasian, 12.9\% Asian-American/Asian, 2.2\% African-American/Black/African, 1.7\% Mexican-American/Chicano, 3.4\% Other Latino, 1.4\% Native American, and .7\% Native Hawaiian/Pacific Islander, 3.1\% Mixed Ethnicity, and 1.2\% other. In addition, 99\% were U.S. citizens ( $2 \%$ with dual citizenship) or permanent residents, and $1 \%$ were international students from U.S. institutions; 50\% attended small liberal arts colleges, 39\% private universities with both undergraduate and graduate programs, $10 \%$ state universities, and 1\% other. Of these students, 85\% were juniors and 15\% seniors, and most participants were either $20(64 \%)$ or 21 years old (27\%).

Classes in the program in which students were enrolled were taught in English, and students could choose to enroll in Danish language study (required by some home institutions). The program provided multiple options for cultural integration, such as host family living, buddy programs with local Danes, and extracurricular activities with Danes, such as sports and clubs. Each student was enrolled in a core course that included two study trips during the semester, one in Denmark and/or Sweden and the other a week-long trip to another country, and students were given additional breaks to travel on their own.

\section{Procedure}

Students responded to an online survey that they received by email from the first author during the final weeks of their study abroad semester during Fall 2013. They were assured that results were being collected independently of the program in which they were enrolled, that the data would be reported only in aggregate form, and that names would be stripped from the data set used for analyses. All participants provided informed consent. The Middlebury Institutional Review Board 
reviewed and approved the research. Participants were compensated by participation in a raffle for Amazon gift certificates.

\section{Measures}

The survey was administered using Key Survey, and the data were downloaded into SPSS [Statistical Package in the Social Sciences]. Questions included both close-ended Likert-type scale items and open-ended questions. We used measures created for our previous studies, existing instruments, and assessments designed for this particular study or adapted from existing measures. We assessed student-parent communication patterns, connections with friends at home, use of Facebook and other social media, self-regulation and parental regulation, autonomy, personal and cultural learning, and advice to others studying abroad (in addition to other measures not utilized in the following analyses). Students also provided demographic information. Specific measures included:

Student-parent communication: This section of the survey assessed the form and frequency of communication using each of a variety of modes (cell phone, texting, email, etc.), as well as who initiated contact, along with measures of satisfaction and other related items. We replicated measures from our previous studies and developed a few items pertinent to study abroad.

Overall communication with others: We asked about amount of time spent communicating digitally with anyone on a typical day and other similar questions.

Comparison of ability to connect electronically with others (home vs study abroad): Students were asked to compare their ability to be connected abroad in comparison with on their home campus, and, if they experienced less ability to connect, to register their response and to comment.

Use of Facebook and other social media: Questions included the amount of time spent on Facebook in a typical day, seven items regarding perceptions of Facebook and other social media use, and an open-ended question about the use of Facebook while abroad.

Autonomy development: The survey included both the Adolescent Autonomy Questionnaire (AAQ) (Noom, Dekovi'c, \& Meeus, 2001) and the Emotional Autonomy Scale (EAS) (Steinberg \& Silverberg, 1986). The AAQ consists of three separate scales, each measured by five items that form an integrative model of autonomy: Attitudinal Autonomy, Emotional Autonomy, and Functional Autonomy. The EAS is a 20-item assessment of autonomy, comprised of four scales (Parents as People, De-idealization, Non-dependence, and Individuation). We chose to focus on the 4-item scale of Non-dependence, as the best representation of independent functioning (sample reversed item: "When I've done something wrong I depend on my parents to straighten things out for me"). Each item is measured on a 1-4 scale from "strongly disagree" to "strongly agree."

Parent and self-regulation: These constructs were assessed using the Parent Academic Regulation scale (nine items, e.g., "My parents edit the papers I write", $\alpha=.77$ ), the Parent Behavior Regulation scale (ten items, e.g., "Your parents...Reminded you to eat well", $\alpha=.83$ ), and the Student Academic Regulation Scale (nine items, e.g., "I plan ahead for academic assignments", $\alpha=.84$ ), all developed for our previous studies from reviews of the literature, and with high reliability. In 
addition, we asked questions regarding parental involvement written for this study (e.g., Your parents... "expressed worry about your being abroad"). Responses were provided on a 1-5 scale from "never" to "very often" in the case of parental regulation and concerns, and from "not at all true" to "very true" in regard to student self-regulation.

Personal and cultural learning: This measure consisted of 15 items adapted from multiple sources, including study abroad evaluation forms from various institutions, including Abroad101, Middlebury College, and the study abroad program where this research was conducted. Students were asked to examine their goals for study abroad and then consider the question "To what extent do you think you achieved any of the following during your time abroad?" and to respond on a 1-5 scale, from "not at all true of me" to "very true of me."

Factor analysis using a varimax rotation, followed by a review of eigenvalues over 1.0 and an examination of the scree plot indicated three scales, which we identified as Personal Challenge (five items, e.g., "I challenged myself," 'I tried new things," $\alpha=.86$ ), Cultural Learning (four items, e.g., "I learned more about other cultures," "I learned more about my own cultural values," $\alpha=.78$ ), and Positive Learning Experience, (e.g., three items, e.g., "I am pleased with my overall learning experience," $\alpha=.72)$.

We asked students to indicate degree of agreement (on a 4-point scale from "strongly disagree" to "strongly agree") with the statement "Study abroad has changed my life," and then to elaborate on their responses. We also solicited what advice they would offer others about studying abroad. In addition, we asked students to indicate their housing arrangements and the cultural activities in which they were involved.

\section{Results}

\section{Connectivity While Abroad}

Connectivity abroad is often less than what students experience on their home campuses or have come to expect. In response to the question of how participants viewed connectivity abroad in comparison to their home campus experience, $80 \%$ of the participants reported that they were less able to be connected abroad than they were accustomed to on their home campuses. Many were accustomed to smartphones and data plans and found it an adjustment to be on the streets of a new city, during commutes, or in other public places with an inability to contact others or to access the internet. Asked how they felt about it, however, responses were mixed. Students were given a set of choices and could include all that applied, and the most common response was "a sense of freedom" (55\%), followed by "glad to have more face-to-face time with peers" (47\%), and then a set of more negative emotions, topped by frustration, boredom, and anxiety (Chart 1). 
"If you found yourself with less potential to connect, how did you feel about it?

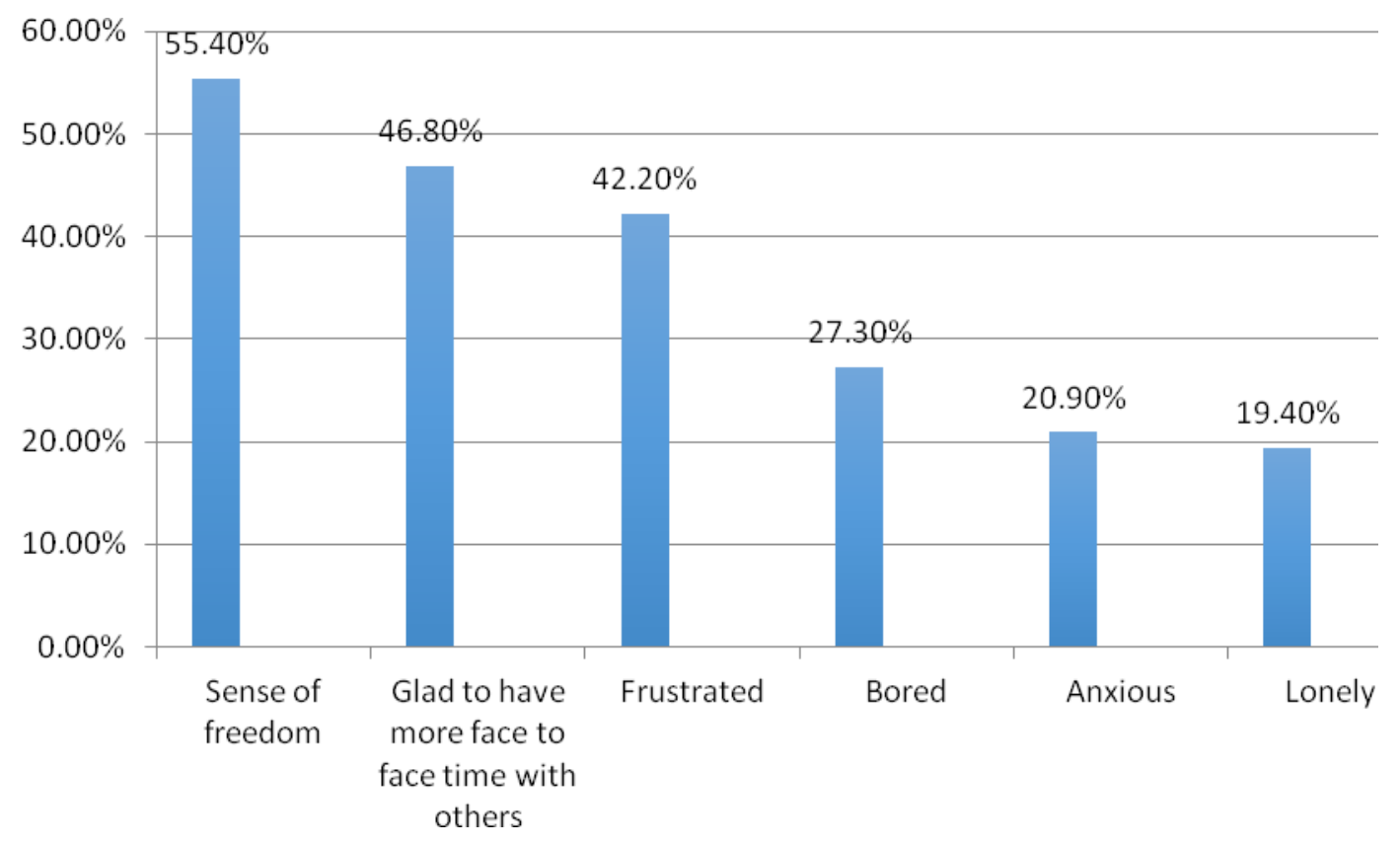

Chart 1. Responses to Decreased Connectivity

Given an opportunity to elaborate about their reactions to diminished connectivity, many students spoke of the positive effects, with comments such as "I began to have much greater experiences when I wasn't connected," "I liked being 'off the grid' because I couldn't feel bad that I wasn't responding to others, so I felt more immersed in my present situation," and "Absolutely amazing!! I had so many deeper conversations with friends because we weren't constantly checking our phones!" Some spoke of both the positive and negative aspects, as well as what they had learned from the experience. As one student noted:

I loved the freedom of having less connection and in certain situations it was very rewarding to go on without any ways of connecting and still surviving. Whenever I was preoccupied with adventures or consumed by conversations and people, life was completely grand. In contrast, sometimes in the down time I fought off the feeling of loneliness and disconnect. When this happened I just made more of an effort to change my mindset and be grateful and present in the moment. I learned that here, I hope.

By contrast some had become so accustomed to the safety net that technology seems to provide that they found it alarming to be without it. And one resorted to capital letters to express her fear: "I'm usually scared when I don't have phone service because of safety. NO ONE WILL KNOW IF I DIE."

\section{Connection with Parents while Abroad}

Asked how much they connected with parents while abroad, compared to communication with parents when at their home institutions, most students reported that it was much less or somewhat less $(52 \%)$, or about the same $(32 \%)$, with only $15 \%$ reporting more contact than was typical at home. However, the actual self-reported communication with parents, when all communications 
forms were summed, was 22.4 times per week on average. This finding was comparable to results from a recent study of U.S. college students on their home campus, as noted earlier (22.1 times per week) (see Table 1). The primary means of communication with parents while abroad, in descending order, were email, followed by texting, instant messaging, and cell phone calls. The amount of contact that was reported as student-initiated vs. parent-initiated was roughly equal, with studentinitiated contacts slightly higher (11.4 vs 10.8). We also asked how many days per week they had contact with parents, and the average was 4.0 days with mothers and 2.9 days with fathers, also comparable to data collected with U.S. students in 2013.

Table 1. Frequency of Communication with Parents

\begin{tabular}{|l|l|l|}
\hline Initiation of contact & Students at home campus (Fall 2012) & Students studying abroad (Fall 2013) \\
\hline Student-initiated & 11.0 & 11.4 \\
\hline Parent-initiated & 11.2 & 10.8 \\
\hline Total contacts & 22.1 & 22.4 \\
\hline
\end{tabular}

Most students apparently do not view this amount of contact with home as a burden and generally report a high degree of satisfaction with the amount of communication, with only $3 \%$ of students wanting less contact with mothers and only $2 \%$ wanting less with fathers, and many wanting more (21\% and 30\%, respectively). They do not, however, believe that their parents are satisfied with this amount of communication, with 54\% responding that they think their mothers would like even more frequent communication, and $42 \%$ of the dads. Only $1 \%$ reported that they thought their parents would want less communication. In addition to such frequent communication, many parents (55\%) also visited during the semester abroad, and $7 \%$ accompanied the students during their move abroad.

Frequent contact allows for parents to communicate concerns they may have about the study abroad experience, and many students reported that parents had "very often" or "often" expressed worry about their being abroad (38\%), and 58\% indicated parents had expressed anxiety about their well-being. Many students were expected to contact parents when they were traveling or on study tours (27\% reported "often" or "very often") or when they returned from such travel (46\%). Some students were also aware that their parents had intervened on their behalf with the host program $(12 \%)$ or their home institution $(9 \%)$. Notably, parents also used their communication to foster encouragement, with $73 \%$ of students reporting that their parents had encouraged involvement in Danish culture.

\section{Parental Contact and Correlations with Psychosocial Measures}

Technology also makes it possible for parents to utilize their contact with students while abroad to assist in the regulation of academic work and behavior. Asked about a series of such parental behaviors during the semester abroad, 38\% reported that parents reminded them to study, 23\% report that parents had proofed their papers, $20 \%$ that parents edited their papers, and 10\% that parents helped them prepare for tests. These figures are remarkably similar to data collected in our previous studies, suggesting that parental regulation behavior continues abroad unabated, now that 
technology makes frequent contact possible. We also correlated the two scales of parental regulation to frequency of contact and found statistically significant but very weak correlations (.18** with parent academic regulation, $.14^{* *}$ with parental behavioral regulation.)

In regard to autonomy development, correlations were in the expected direction, with frequency of communication negatively related to autonomy development $\left(-.11^{* *}\right)$ and nondependence $\left(-.14^{* *}\right)$, but these were also very weak correlations, albeit statistically significant. In addition, we asked students to report on their growing independence in qualitative measures, asking "What have you learned to do for yourself this semester that you hadn't done before?" Responses included a variety of comments that suggested growing autonomy in the areas of self-governance, e.g., "Make big decisions without discussing them with anybody"; independence, e.g., "Go blindly into a new country and make friends when I don't speak the language," "Learned to travel solo," and personal responsibility, "How to care for myself completely on my own when I'm sick." Some respondents also reported on growing comfort with less technology, e.g., "Learned to enjoy down time alone (like on the train or metro with no wifi)." In addition, they reported on the more delightfully mundane aspects of new experiences abroad, citing that they had learned to "put a duvet cover on," "use a shower that's connected to a sink," "cook a quiche" and "navigate without GPS."

\section{Communication with Friends while Abroad and Use of Facebook}

In addition to communicating with their families using a range of technological devices, apps, and social media, students studying abroad were communicating with friends at home and with new friends they made while abroad. When asked to report the amount of time in a typical week spent communicating with others using computers, cell phones, or other devices, participants reported an average of 1.2 hours per day. They listed a wide variety of means to do so, such as Facetime, Skype, Whatsapp, Kakao, Facebook messaging and chat, Google Hangout, WeChat, Viber, etc.

When asked to comment on their communication with others, students often described the double-edged sword of such technological connections. As one student wrote, "The Internet is both a curse and a blessing. It's great to stay connected with people from home but it definitely provides a crutch and makes it easier to keep yourself in a bubble and not be forced to go out and meet new people." Others reflected on the emotional impact of these connections: "Having real conversations with my truly close friends or my boyfriend was tough. It was a temporary fix that made me so happy while we were talking but so upset after we hung up. It's a frustrating paradox: you talk because you miss them, but talking makes you miss them more." Some were simply glad to have the tools, in order to meet family expectations: "Viber has been very helpful when I talk to my family. My mom likes to be in touch every day."

In addition to communicating directly with friends at home, those who study abroad can use social media to view what other classmates are doing (whether at home or also abroad) and post updates on their own experiences, a form of indirect communication. Participants reported spending an average of 1.6 hours per day on Facebook while abroad. When asked to respond to the item "Sometimes I think more about how to present an experience on Facebook than actually experiencing it," 31\% strongly or moderately agreed. Many students acknowledged that Facebook often fostered a "fear of missing out" (FOMO), with 65\% strongly or moderately agreeing that Facebook and other social media sites led them to feel they were missing out at their home campus; 
only $22 \%$ disagreed. Students commented on this with such statements as "There's no reason to be looking at the stuff while you're at the Eiffel tower or Coliseum, but it's hard not to if you have the access. It was definitely better not to have wifi while traveling." Asked to give advice to other students, one noted: "Everything and everyone will still be there when you get home, I promise." Overall, however, $65 \%$ of those surveyed disagreed with the statement "Sometimes I wish I had less contact with friends at home so I could experience life abroad more fully."

\section{Study Abroad Satisfaction and Learning}

Overall, students in this program were highly satisfied with their experience, averaging 4.5 out of 5 when asked to rate their study abroad experience. Satisfaction was only weakly correlated with time per day spent communicating with others (.14**). We also used three scales to assess the student experience, defined as cultural learning, personal challenge, and positive learning experience. We found highly significant gender differences in the first two, with women scoring higher on both, and not the third, indicating that males and females were equally satisfied with the study abroad experience, but that women gained more in terms of cultural learning and personal challenges. In addition, functional autonomy was positively correlated with both cultural learning $(.23 * *)$ and positive learning experience $\left(.20^{* *}\right)$.

We also examined the relation between the cultural learning scale and various aspects of the cultural experience offered by the program or within the students' control. In terms of housing, students living in a Danish Folkehojskole (folk school) or with a host family, the two housing options that offered the most interaction with Danes, reported the highest scores on cultural learning, 4.47 and 4.18 (on a 5-point scale) respectively, with students in all other housing options averaging below 4.0 on this measure. Cultural learning was positively correlated, in descending order, with getting together socially with Danish students $\left(.28^{* *}\right)$, "exploring Copenhagen on my own" (.22**), shopping for groceries and preparing meals (.19**), participation in sports groups with Danes $\left(.14^{* *}\right)$, commuting by public transit $\left(.11^{* *}\right)$, and participation in other interest groups with Danes $\left(10^{* *}\right)$.

\section{Study Abroad as a "Life-changing experience: The Student View"}

In response to the question about the extent of agreement with the statement "Study abroad has changed my life," the mean response on a 5-point scale was 3.29, and students elaborated in detail. Typical responses included:

"I have learned more about my own culture as experienced through the eyes of people in another culture."

"Study abroad has given me a greater overall sense of the world and my place in it, especially with an eye toward recent US politics from outside the country."

"I want to apply some of the aspects of Danish life into my life: more simplistic and less competitive, more focused on the family, equality, healthy lifestyles, biking."

"I have seen so many things that I always dreamed of seeing and I can bring that back into my life. I have experiences to write about. But I didn't become a Dane."

"It has opened my eyes to travel and what it means to explore and how to do it. It has challenged my beliefs and made me more aware of how I interact and come off to others. It 
has made me even more grateful for my life and it has helped me grow and understand myself and develop who I am!!”

I've grown up, learned how to fend for myself, gained newfound personal and cultural awareness, traveled extensively throughout an entire continent, gained a great deal of independence, and have just generally become a more fully formed human being. The lessons I've learned about taking care of myself, emotionally, socially, and physically speaking, will help me for the rest of my life."

"I feel like I'm almost a totally different person than before I came here. I have gotten very involved in Danish culture and made long lasting friendships with a number of Danes. I've taught myself a good amount of Danish language and plan on returning here either next summer or when I graduate."

\section{Advice to Others Studying Abroad}

We also asked students what advice they would offer others studying abroad. Content analyses of the responses to the open-ended question suggested the following primary categories: Be adventurous/ try new things (44\%), Experience the culture (15\%), Befriend locals (15\%), Limit technology use and communication with home (8\%), Travel more $(7 \%)$, Do things alone $(6 \%)$, Get to know your city $(6 \%)$, and Budget well (4\%).

Although we did not ask specifically for advice about technology, those who chose to address it had comments such as:

"The technology, while your greatest ability to communicate, is often a hindrance on your experience abroad. Cut your phone off, and take the world in."

"...stay away from cellphones for a bit each day to practice being more fully in the present. Many students tend to focus on being on Facebook and other social media to a point where it blocks them from experiencing study abroad to the fullest extent possible.”

"... know that life at home is going to continue without you and that is okay. Don't dwell on what you are missing there or you will miss out on what is going on here."

"Enjoy the time you have traveling, and stop looking for a wifi signal every minute! Enjoy just being on your own and take time to explore some things without friends and see what happens!"

Students also offered broad advice about getting out of one's comfort zone, arriving with an open mind, and not being afraid to be alone, as well as about cultural immersion and the value of one's housing choices. As one student said: "Immersion is NOT going to a bar and meeting Danes. It is eating dinner with them every night, looking forward to returning home and hanging out with them, talking about cultural differences, and making memories." Another echoed this advice more broadly: "Try your hardest to integrate with the native population. You will have time to hang out with Americans any other semester."

\section{Discussion}

The era has ended when students went abroad, fully immersed in a new culture, and had only sporadic contact with family and friends at home, and this claim is well-known by study abroad 
professionals. What this current study does, however, is quantify the amount of connection, address some of the implications of the ongoing communication with home, and report on students' perceptions of this continued contact while abroad. Overall, we found that students are in regular, almost daily contact with parents, communicating at roughly the same rate as a comparable group of college students on a U.S. campus during a regular semester at home. These contacts occur through multiple means, and these modes of connection continue to expand. Moreover, student initiation and parent initiation of contact are roughly equal, as in our previous studies, which runs counter to a common narrative that "helicopter parents" are driving the connection. If anything, student-initiated contact may be underreported in these studies, given the self-report nature of the data and the lack of parent reported data for corroboration. The fact that students are communicating abroad at the same rates as at home indicates the ubiquitous nature of communication between college students and their parents at this point in time. This customary practice is now easily transportable into new situations and locations and can continue unabated. The ease of such communication may make it especially important to understand the implications and to address the ways in which such communication can be used in positive ways.

We found that some parents are continuing to regulate and monitor from afar, in percentages equivalent to what has been reported by students studying at home. Frequent contact also leads students to be aware of parental concerns about their experiences abroad, and we do not know the extent to which this affects student well-being while abroad and how it may hinder autonomy development. Students do, however, report growing independence during the semester abroad. Furthermore, students are in contact with numerous others beyond family members, including friends at home, friends abroad in other locations, and new friends. In addition, they are spending large amounts of time each day on Facebook, which creates an awareness of others' experiences either at home or abroad, inviting comparisons that are often detrimental to self-esteem and mental health (Tandoc, Ferrucci, \& Duffy, 2015). Although in hindsight many students urged others to limit time on Facebook during study abroad, this may be hard for students to do, particularly when lonely or homesick. A central concern, however, is simply the amount of time spent connecting with those at home and what might be displaced in the way of activities that would lead to greater cultural integration and learning.

We hope these findings will be of use to those who work with students preparing for study abroad and to those who are on-site, as well as in providing guidance to parents before and during the study abroad experience. We also recognize limitations to this research. Although the students came from a wide array of primarily U.S. colleges and universities, they are in a single European study abroad program, with no formal language requirement, and in a city where English is widely spoken. Future research might involve multiple programs, including those with language immersion components. This was also a correlational study and we are thus not able to make causal connections between student communication with home and the psychosocial measures we utilized. Our study was also limited to data collection at a single time point, the final weeks of a study abroad semester. We had a slightly higher percentage of female respondents than the overall pattern of gender differences in for U.S. students studying abroad (76\% vs 65\%, according to Open Doors, 2014). 


\section{Implications}

Findings from this study suggest implications for students, parents, education abroad advisors, and on-site faculty and staff, before and during the study abroad experience. The disconnect between students' perceptions of how connected they were abroad with how often they were actually communicating with friends and family at home and the amount of time they are spending on social media indicates that students may benefit from being made aware of the time spent connecting with those at home and how it may detract from cultural immersion. Students may need to be coached about the potential effects of the digital tether on their cultural integration and personal development. Advisors can emphasize the findings from this study and caution students in pre-departure advising and orientations regarding the potentially negative consequences of being too "connected" with home while they are abroad. Challenging the "fear of missing out" is especially important, helping students, as one student noted, to "try to be in the moment and not back at home." Qualitative data from this study can provide students with meaningful advice from peers who have returned from studying abroad and have experienced the pros and cons of the electronic attachment to home and the enticement of social media, texting, Skyping, Facetime, etc. Advisors might highlight the mixed feelings students seem to have about the amount of connection with home while abroad, accentuating the sense of freedom and appreciation for face-to-face interactions that the majority of students seem to glean from being less connected.

All of these points could be reiterated in on-site orientations, where perhaps students may be more receptive, after they are in-country and feel the lure of being in close touch with family and friends at home. After arrival, they also may be experiencing stress from the new cultural environment, perhaps leading to the use of technology as a tool of avoidance. Also on-site, the findings of this study suggest that it may be pertinent for program staff to challenge students' insistence on having constant access to wifi, explaining potential benefits of less connectedness for cultural immersion and personal growth. On-site staff could also facilitate sessions during orientation, as well as throughout the program, for students to discuss and reflect on their technology use. Soon after arrival, students might also benefit from workshops or trainings on how to utilize technology to enhance the study abroad experience, such as using navigation tools and learning about their host city and country, as well as using social media to involve themselves in local activities and events and connect with new friends from the host country. Students are well-aware of the technological tools and resources needed for such navigation and involvement at home - in fact they are likely more tech savvy than many study abroad staff - but they may benefit from on-site staff equipping them with local equivalents in the study abroad setting. These trainings could also highlight and provide concrete resources for how students can seek support abroad in ways that avoid relying on the technological connection with home as their primary support. It may be important for staff to ensure that sessions and discussions do not imply to students that their use of technology and connectedness with home is being monitored, controlled, or judged; rather, the emphasis could be placed on awareness of the possible implications of excessive use of technology and connectedness with friends and family, and how students can utilize technology to enhance and encourage cultural engagement.

Education and training on these matters is similarly essential for parents. Many study abroad programs have specific materials directed to parents; materials could include information about the implications of excessive and frequent communication with their student abroad, and the 
importance of encouraging students' independence, self-reliance, and cultural involvement. This study indicates that parents continue to regulate their students while they are abroad, and that there are negative consequences associated with parental regulation. This study also showed, however, that the majority of parents encouraged their students' cultural involvement; perhaps there are ways for this proclivity to be maximized as we work with parents of study abroad students. Parent information could include suggestions for cultural engagement, which they could recommend to their students, such as participation in home stays or visiting host family programs, community service or volunteer work, and participation in sports or special interest clubs, to name only a few possibilities. This study confirmed hypotheses that cultural learning was correlated with involvement in activities and groups with people from the host country, as well as living with a host family, which is perhaps obvious to education abroad professionals, but importantly, this study also showed cultural learning to be correlated with functional autonomy and a positive learning experience.

\section{Future Research}

This study suggests a multitude of areas for future research. Similar research could be conducted in a language immersion program, or in a program in which students have different levels of language fluency or in locations where English is not widely spoken. For example, researchers might explore if students are even more reliant on contact with home when they are living in communities where command of the local language is essential for daily living. In addition, researchers could investigate communication with home by those studying in areas of the world where technology is less available. Further, this study could be replicated with different program types, such as those suggested by Engle and Engle (2003): study tours, short-term study, crosscultural contact programs, cross-cultural encounter programs, and cross-cultural immersion programs. There are many distinguishing factors in these various program types that could be analyzed in relation to students' electronic connection with home, such as, but not limited to: program length, students' encouraged or required involvement in cultural activities, and direct enrollment in a local university contrasting with programs where students take only in-house courses.

As mentioned, the field of education abroad has seen an increased emphasis on student learning and assessment and measuring intercultural competence development. Future research could include investigating students' involvement with social media and their communication with home and how these affect their learning and intercultural competence development. Tools such as the Intercultural Development Inventory (Hammer, 2012) could be utilized to assess students' predeparture and post-program intercultural competence and how their stages of development may be affected by the form and frequency of communication with home.

Technology and the increasing ability to connect with home through multiple means have altered the study abroad experience for many. As the field of education abroad continues the discussion around student learning and intercultural competence assessment, and develops new tools to increase students' learning abroad, it should not be forgotten that the digital tether with home is fundamental to the conversation. 


\section{Acknowledgments:}

We are grateful to the staff of the DIS Study Abroad in Scandinavia program for their support and cooperation, and to the Middlebury Faculty Development Fund and Middlebury Faculty Research Assistant Fund for support for this research. We also thank the reviewers for very helpful comments and suggestions.

\section{References}

Arnett, J. J. (2000). Emerging adulthood: A theory of development from the late teens through the twenties. American Psychologist, 55(5), 469-480.

Arnett, J. J. (2015). Oxford handbook of emerging adulthood. Oxford: Oxford University Press.

Bell, K. L., Allen, J. P., Hauser, S., \& O'Connor, T. (1996). Family factors and young adult transitions: Educational attainment and occupational prestige. In J. Graber, J. Brooks-Gunn \& A. Petersen (Eds.), Transitions through adolescence. Hillsdale, N.J.: Erlbaum.

Cohen, A. D., Paige, R. M., Shively, R. L., Emert, H., \& Hoff, J. (2005). Maximizing study abroad through language and culture strategies: Research on students, study abroad program professionals, and language instructors. Final Report to the International Research and Studies Program, Office of International Education, U.S. Department of Education. Minneapolis, MN: Center for Advanced Research on Language Acquisition, University of Minnesota.

Deardorff, D. K. (2011). Assessing intercultural competence. New Directions for Institutional Research, 2011(149), 65-79.

Engle, L. \& Engle, J. (2002). Neither international nor educative: Study abroad in the time of globalization. In W. Grunzweig \& N. Rinehart (Eds.), Rockin in Red Square: Critical approaches to international education in the age of cyberculture (pp. 25-39). Piscataway, NJ: Transaction Publishers.

Engle, L. \& Engle, J. (2003). Study abroad levels: Toward a classification of program types. Frontiers: The Interdisciplinary Journal of Study Abroad, 9, 1-20.

Engle, L. \& Engle, J. (2012). Beyond immersion: The American University Center of Provence experiment in holistic intervention. In M. Vande Berg, R. M. Paige, \& K. H. Lou (Eds.), Student learning abroad: What our students are learning, what they're not, and what we can do about it (pp. 284-307). Sterling, Virginia: Stylus Publishing.

Forum on Education Abroad (2015).Standards of good practice for education abroad, 5th Edition. Retrieved from https://forumea.org/resources/standards-of-good-practice/

Hammer, M. R. (2012). The intercultural development inventory: A new frontier in assessment and development of intercultural competence. In M. Vande Berg, R.M. Paige, \& K. H. Lou (Eds.), Student learning abroad: What our students are learning, what they're not, and what we can do about it (pp. 115-136). Sterling, Virginia: Stylus Publishing.

Hofer, B. K. (2008). The electronic tether: Parental regulation, self-regulation, and the role of technology in college transitions. Journal of the First-year Experience \& Students In Transition, 20(2), 9-24.

Hofer, B. K., Kennedy, E., \& Hurd, K. (August, 2006). From "other regulation" to "self regulation": Parental contact and influence during the transition to college. Paper presented at the annual meeting of the American Psychological Association, New Orleans.

Hofer, B. K. \& Moore, A. S. (2010). The iConnected Parent: Staying close to your kids in college (and beyond) while letting them grow up. New York: Free Press.

Hofer, B. K., Souder, C., Kennedy, E., Fullman, F. E., \& Hurd, K. (2009). The electronic tether: Communication and parental monitoring during the college years. In M. K. Nelson and A. I. Garey, (Eds.). Who's watching? Practices of surveillance in contemporary families (pp. 277-294). Nashville: Vanderbilt University Press.

Hofer, B., \& Yu, S. (2003). Teaching self-regulated learning through a "Learning to learn" course. Teaching of Psychology, 30(1), 30-37. 
Hofer, B., Yu, S., \& Pintrich, P. (1998). Teaching college students to be self-regulated learners. In D. H. Schunk \& B. J. Zimmerman (Eds.), Self-regulated learning - from teaching to self-reflective practice (pp. 57-83). New York: Guilford Press.

Hoffa, W. W. \& DePaul, S. C. (2010). A history of U.S. study abroad: 1965 to present. Carlisle, PA: Frontiers: The Interdisciplinary Journal of Study Abroad/The Forum on Education Abroad.

Huesca, R. (2013, January 14). How Facebook can ruin study abroad. The Chronicle of Higher Education. 59 (19). http://chronicle.com/article/How-Facebook-Can-Ruin-Study/136633

Ingraham, E. C. \& Peterson, D. L. (2004). Assessing the impact of study abroad on student learning at Michigan State University. Frontiers: The Interdisciplinary Journal of Study Abroad, 10, 83-100.

Mikal, J. P. (2011). When social support fits into your luggage: Online support seeking and its effects on the traditional study abroad experience. Frontiers: The Interdisciplinary Journal of Study Abroad, 21, 17-40.

Mikal, J. P. \& Grace, K. (2012). Against abstinence only education abroad: Viewing internet use during study abroad as a possible experience enhancement. Journal of Studies in International Education, 16(3), 287-306.

Noom, M. J., Deković, M., and Meeus, W. (2001). Conceptual analysis and measurement of adolescent autonomy. Journal of Youth and Adolescence. 30, 577-595.

Open Doors Report on International Educational Exchange (2014). Institute of International Education. http://www.iie.org/Research-and-Publications/Open-Doors/Data/US-Study-Abroad

Paige, R. M. \& Vande Berg, M. (2012). Why students are and are not learning abroad. In M. Vande Berg, R. M. Paige, \& K. H. Lou (Eds.), Student learning abroad: What our students are learning, what they're not, and what we can do about it (pp. 29-58). Sterling, Virginia: Stylus Publishing.

Root, E. and Ngampornchai, A. (2012). "I came back as a new human being": student descriptions of intercultural competence acquired through education abroad experiences. Journal of Studies in International Education. 17(5), 513-532.

Ross, M., Salisbury-Glennon, J., Guarino, A., Reed, C., \& Marshall, M. (2003). Situation self-regulation: Modeling the interrelationships among instruction, assessment, learning strategies and academic performance. Educational Research and Evaluation, 9(2), 189-209.

Salisbury, M. H., An, B. P. \& Pascarella, E.. (2013). The effect of study abroad on intercultural competence among undergraduate college students. Journal of Student Affairs Research and Practice, 50 (1), 1-20.

Sherman, L. E., Payton, A. A., Hernández, L. M., Greenfield, P. M., Dapretto, M. (May 31, 2016) The power of the like in adolescence: Effects of peer influence on neural and behavioral responses to social media. Psychological Science OnlineFirst, 1-9, doi:10.1177/0956797616645673

Smith, A. (April 1, 2015). U. S. Smartphone use in 2015. Pew Research Center. http://www.pewinternet.org/2015/04/01/us-smartphone-use-in-2015/.

Steinberg, L. (2001). We know some things: Parent-adolescent relationships in retrospect and prospect. Journal of Research on Adolescence, 11(1), 1-19.

Steinberg, L., \& Silverberg, S. (1986). The vicissitudes of autonomy in early adolescence. Child Development, 57(4), 841-851.

Sutton, R. C. \& Rubin, D. L. (2004). The GLOSSARI project: initial findings from a system-wide research initiative on study abroad learning outcomes. Frontiers: The Interdisciplinary Journal of Study Abroad, 10, 65-82.

Tandoc, E. C., Ferrucci, P. \& Duffy, M. (2015). Facebook use, envy, and depression among college students: Is facebooking depressing? Computers in Human Behavior, 43, 139-146.

Turkle, S. (2011). Alone together: Why we expect more from technology and less from each other. New York: Basic Books.

Twombly, S. B., Salisbury, M. H., Tumanut, S. D., \& Klute, P. (2012). Special Issue: study abroad in a new global century-renewing the promise, refining the purpose. ASHE Higher Education Report, $38(4), 1-152$. 
Vande Berg, M. Connor-Linton, J., \& Paige, R. M. (2009). The Georgetown Consortium Project: Interventions for student learning abroad. Frontiers: The Interdisciplinary Journal of Study Abroad, $18,1-74$.

Vande Berg, M., Paige, R. M., \& Lou, K. H. (2012). Student learning abroad: What our students are learning, what they're not, and what we can do about it. Sterling, Virginia: Stylus Publishing.

Vande Berg, M., Quinn, M., \& Menyhart, C. An experiment in developmental teaching and learning: The Council on International Educational Exchange's seminar on living and learning abroad. In M. Vande Berg, R. M. Paige, \& K. H. Lou (Eds.), Student learning abroad: What our students are learning, what they're not, and what we can do about it (pp. 383-407). Sterling, Virginia: Stylus Publishing.

Wooley, S. (2013). Constantly connected: the impact of social media and the advancement in technology on the study abroad experience. Elon Journal of Undergraduate Research in Communications, 4(2), http://www.studentpulse.com/a?id=822. 